\title{
Internal fixation of femoral shaft fractures in children by intramedullary Kirschner wires (a prospective study): its significance for developing countries Shashank D Chitgopkar*
}

\author{
Address: Department of Orthopaedics, King Khalid hospital, Najran, Saudi Arabia \\ Email: Shashank D Chitgopkar* - shashankdc@ hotmail.com \\ * Corresponding author
}

Published: 29 March 2005

BMC Surgery 2005, 5:6 doi:10.1 186/147/-2482-5-6

This article is available from: http://www.biomedcentral.com/I47/-2482/5/6

(C) 2005 Chitgopkar; licensee BioMed Central Ltd.

This is an Open Access article distributed under the terms of the Creative Commons Attribution License (http://creativecommons.org/licenses/by/2.0), which permits unrestricted use, distribution, and reproduction in any medium, provided the original work is properly cited.
Received: 03 March 2004

Accepted: 29 March 2005

\begin{abstract}
Background: To evaluate internal fixation by intramedullary Kirschner wires as a surgical technique in the treatment of femoral shaft fractures in children by a prospective study.

Methods: 17 femoral shaft fractures at various levels in 16 children aged 2-15 years were treated by closed intramedullary Kirschner wiring under image intensifier control between May 2000 and October 2003. No external splint was used.
\end{abstract}

Results: Fracture union was achieved in 6-14 weeks. Non-weight bearing crutch walking was started 2-3 days after surgery. Full weight bearing started 6-14 weeks. Average operative time was $40 \mathrm{~min}$ (range 20-72 $\mathrm{min}$ ). Wires were removed after 8-22 weeks. There were no infections, no limb length disparity. One child had pin track ulceration. A big child of I 4 years had angulation of the fracture.

Conclusion: Intramedullary nailing of femoral shaft fractures in children by stainless steel Kirschner wires is an effective method, which compares well with other studies. It is a simple procedure, which can be easily reproduced. Blood loss is minimal, and the operative time short. There is no need pre-bend the wires in a C or S curve. Stainless steel Kirschner wires are cheap, universally available, and can be manufactured locally. The cost of Image intensifiers is affordable in most of the cities of the developing countries. The hospital does not have to maintain a costly inventory. Provides early mobility, return to home and, school. Gives a predictable clinical pathway and reduces occupancy of hospital beds.

The technique was successfully applied for internal fixation of other diaphyseal fractures in children and some selected diaphyseal fractures in adults. Based on my experience and a review of the literature, I recommend this technique as a modality for treatment of femoral shaft fractures in children aged 2 to 14 years.

\section{Background}

This technique has been used successfully at King Khalid hospital, Najran, Saudi Arabia since 1995.
This prospective study was prompted by a review of earlier reports by Shakeel [1], Salem Al Zahrani [8], and Ligier and Metazieau [6]. 
Fracture treatment in children relies on rapid healing and spontaneous correction of angulated fractures; therefore most of the diaphyseal fractures can be treated by plaster alone. Operative treatment of children's fractures is often looked at critically [2].

Conventional treatment of femoral shaft fractures in children is by traction followed by a hip spica or a Thomas' splint. Conservative treatment of femoral shaft fractures gives good results in children under 5 years of age. But above that age, all such fractures cannot be treated by conservative methods. There is a possibility of loss of reduction and malunion. Plaster immobilisation has its own complications like pressure sores, nerve palsies, soiling of the skin and the plaster, breakage of the plaster, joint stiffness. The child is immobilised and needs an attendant for personal care.

Reeves et al [22] reported that the cost of non-operative treatment is $40 \%$ higher than operative treatment.

In the last few decades, the trend worldwide has been towards some form of fixation for children's fractures, especially the femoral shaft, and the indications for operative management have been widened.

Rush [3] used the intramedullary rods of his design. Intramedullary nailing was made popular by Ender and Simon-Weidner in Europe [4], and by Pankovitch in the United States [5].

Beaty, Austin and Canale [12] studied the preliminary results and complications of interlocking intramedullary nailing of femoral shaft fractures in adolescents.

Gonzalez and Herranz[13] recommend the avoidance of rigid intramedullary nails introduced through the piriformis fossa in children less than 13 years of age. Antegrade intramedullary nailing through the piriformis fossa may cause coxa valga, epiphyseodesis of greater trochanter, thinning of the femoral neck because of damage to the growth plate[13].

Saxer[14] advises the introduction of intramedullary Kuntscher nail through the sub-trochanteric zone or the use of plate and screw.

External fixation has been advocated by Aronson and Tursky[9]. They reported angular deformity and shortening of more than $13 \mathrm{~mm}$ in proximal third femoral shaft fractures treated by conservative means. External fixation has its own complications; pin track infection and refracture $[9,18,19]$. Also, the child has to accommodate an external device.
Compression plating was used by Van Neikerk [10], Ward [11] and Hansen [17]. The disadvantages are the risk of infection, large soft tissue dissection, delayed union, limb length disparity, another large exposure to remove the implants $[10,11]$. The other disadvantages are periosteal stripping, evacuation of fracture haematoma and blood loss. Tarek Mirdad [21] reported blood loss requiring blood transfusion in $41 \%$ of children treated by compression plating. Also, a period of 3-4 weeks of protected weight bearing is recommended after removal of plate and screws.

Ligier and Metaizeau have successfully treated 123 femoral shaft fractures in children by Elastic Stable Intramedullary Nailing (ESIN) [6].

Pradeep Kumar [7], Shakeel [1] and Zahrani [8] recommend the efficacy of Kirschner wires for flexible intramedullary nailing of femoral shaft fractures in children. Shakeel reports reduced psychological trauma on the child and the parents [1].

\section{Methods}

Between May 2000 and October 2003, 17 femoral shaft fractures at various levels in 16 children aged 2-15 years were treated by internal fixation with intramedullary Kirschner wires at King Khalid hospital, Najran, Ministry of Health, Saudi Arabia.

\section{Inclusion criteria}

a. Displaced fractures, with or without comminution.

b. Multiple fractures.

c. Fractures found to be unstable on closed reduction.

d. Fractures which displaced in traction.

e. Fractures in patients with polytrauma and patients under intensive care to facilitate nursing.

f. Irritable patients with brain injury.

g. Associated vascular injury needing repair.

\section{Exclusion criteria}

Undisplaced fractures and fractures in a good position were treated by traction and hip spica.

\section{The goal}

To provide rapid healing of the fracture in a correct position, ease of nursing care, early mobilisation, and return to home and school. 


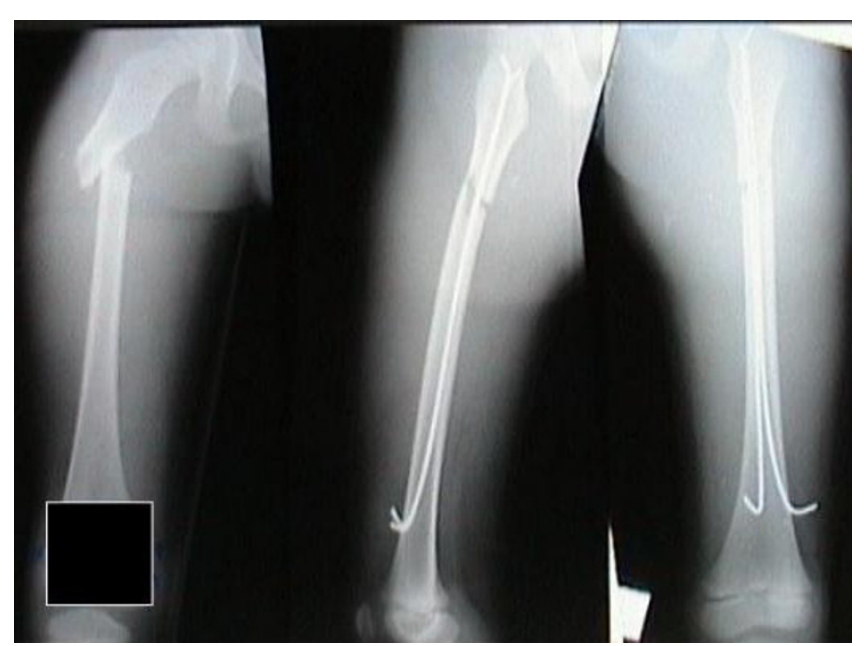

Figure I

Proximal femoral shaft fracture.

\section{Operative technique}

Under general anaesthesia, the patient was placed supine on an orthopaedic table with the feet strapped to the footplates and longitudinal traction applied ensuring correct linear and rotational alignment clinically and radiologically using an image intensifier. 3 small children were operated upon a radiolucent table, traction being applied by an assistant.

2 stainless steel Kirschner wires of $30-45 \mathrm{~cm}$ length and 2.5-3.5 mm diameter (depending on the size of the medullary canal and the child) were prepared by bending them at an approximate angle of $45^{\circ}, 2 \mathrm{~cm}$ from the tip and cutting off the sharp points to prevent inadvertent penetration of the cortex. The wires were not pre-bent in a ' $\mathrm{C}$ ' or ' $\mathrm{S}$ ' curve. The wires were loaded onto a ' $\mathrm{T}$ ' handled introducer with a Jacob's chuck. Two small skin incisions were made proximal to the superior pole of the patella, one laterally and the other antero-medially. Entry portals were made into the distal femoral metaphysis proximal to the growth plate of the distal femur with a sharp bone awl laterally and antero-medially. The wires were introduced retrograde by hand or gentle hammering. The lateral wire was introduced first. The tips of the wire are placed just distal to the growth plates of the greater and lesser trochanters, the bends pointing towards the side of the entry portal [Figure 1]. Angular and rotational malalignment spontaneously corrects on passage of the wires across the fracture.

Image intensifier screening in two planes perpendicular to each other confirmed proper placements of the wires. The tail portions of the wires were bent towards the fracture

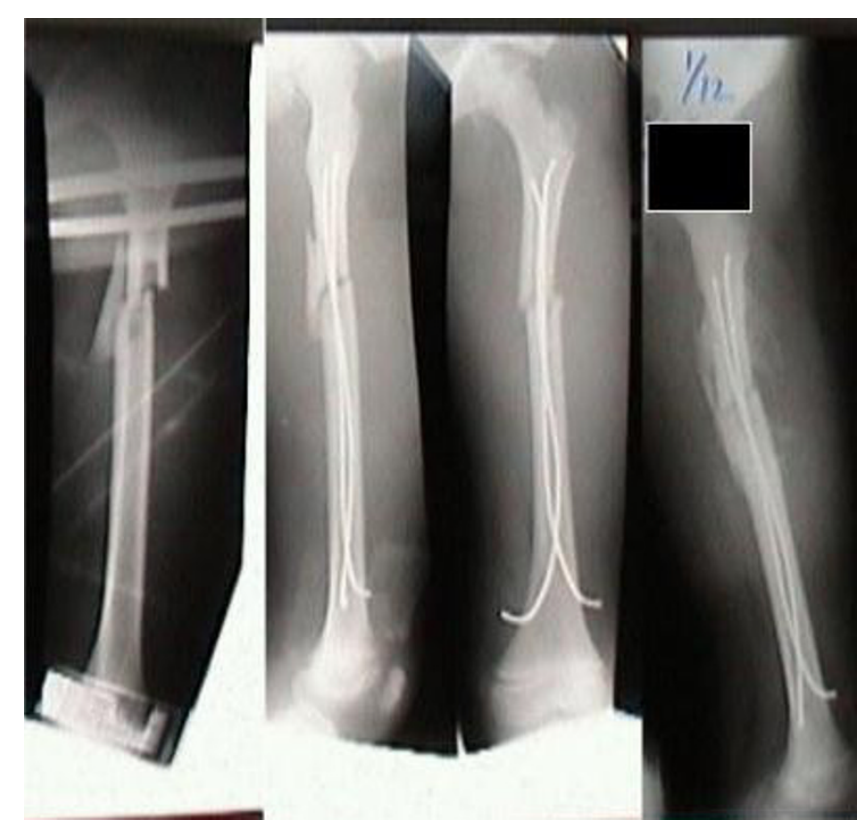

Figure 2

Comminuted proximal femoral shaft fracture.

and cut $1 \mathrm{~cm}$ away from the entry portal in the cortex [Figure 2]. The skin wounds were sutured and dressed. Fracture stability, correct linear and rotational alignment was assessed on table.

All patients had received a pre-operative bolus of intravenous antibiotic.

Antegrade medullary Kirschner wiring was carried out in one small child with a single intramedullary Kirschner wire. The entry portal was on the lateral cortex distal to the growth plate of the greater trochanter.

\section{Post-operative rehabilitation}

No external splint was used except for 2 patients who had ipsilateral tibia and fibula fractures, which were being treated by plaster immobilisation in an above knee plaster cast.

The children were started on non-weight bearing crutch walking and knee physiotherapy 2-3 days after the surgery and were ready for discharge 3-4 days after surgery. The children with polytrauma stayed on for a longer period in the hospital because of associated injuries. Sutures were removed on the $10^{\text {th }}$ day after surgery.

The children were encouraged to attend school three weeks after surgery avoiding sports and physical training. 
Table 2: Details of patients

\begin{tabular}{|c|c|c|c|c|c|c|c|c|c|c|c|c|c|}
\hline Patient & Age & Sex & Side & $\begin{array}{l}\text { Open/ } \\
\text { closed }\end{array}$ & Level of \# & $\begin{array}{l}\text { Operative } \\
\text { time In min }\end{array}$ & $\begin{array}{l}\text { Open/closed } \\
\text { Reduction }\end{array}$ & $\begin{array}{l}\text { Stay fixation } \\
\text { In days }\end{array}$ & $\begin{array}{l}\text { Stay removal } \\
\text { In days }\end{array}$ & $\begin{array}{l}\text { Weight } \\
\text { bearing In } \\
\text { weeks }\end{array}$ & $\begin{array}{l}\text { Time \# } \\
\text { union In } \\
\text { weeks }\end{array}$ & $\begin{array}{l}\text { Time } \\
\text { removal } \\
\text { In weeks }\end{array}$ & $\begin{array}{l}\text { Discharge } \\
\text { In weeks }\end{array}$ \\
\hline I & 6 & $M$ & L & C & U3-M3 jn & 47 & C & 5 & 2 & 6 & 6 & 13 & 17 \\
\hline 2 & 7 & $M$ & $\mathrm{~L}$ & C & U3 & 35 & C & 19 & 3 & 6 & 14 & 20 & 24 \\
\hline 3 & 12 & $\mathrm{~F}$ & Bil. & C & M3 & 75 & C & 13 & 3 & 6 & 10 & 20 & 30 \\
\hline 4 & 2 & $M$ & $\mathrm{~L}$ & C & U3 & 43 & C & 13 & Lost & To & Follow & up & - \\
\hline 5 & 14 & $M$ & $\mathrm{R}$ & C & M3 & 72 & 0 & 13 & 4 & 12 & 12 & 20 & 20 \\
\hline 6 & 12 & $M$ & $\mathrm{R}$ & C & U3 & 36 & C & 06 & 3 & 14 & 14 & 22 & 22 \\
\hline 7 & 8 & $M$ & $\mathrm{R}$ & C & U3-M3 jn & 50 & C & 11 & 2 & 8 & 8 & 16 & 26 \\
\hline 8 & 10 & $M$ & L & C & $\mathrm{M} 3 \mathrm{com}$ & 46 & C & 11 & 3 & 6 & 6 & 16 & 24 \\
\hline 9 & 10 & $M$ & L & C & $\mathrm{M} 3$ & 35 & C & 12 & 2 & 8 & 8 & 20 & 20 \\
\hline 10 & 3 & $M$ & L & C & U3 com & 25 & C & 12 & Lost & To & Follow & up & - \\
\hline 11 & 11 & $M$ & $\mathrm{R}$ & C & M3-L3 jn & 40 & 0 & 61 & 2 & 8 & 8 & 20 & 20 \\
\hline 12 & 4 & $M$ & $\mathrm{R}$ & C & M3 & 20 & C & 8 & 6 & 6 & 6 & 14 & 16 \\
\hline 13 & 14 & $M$ & $\mathrm{R}$ & C & M3 & 32 & $\mathrm{C}$ & 5 & IL nail & - & - & - & - \\
\hline 14 & $31 / 2$ & $M$ & L & C & L3 & 46 & O & 5 & 2 & 4 & 6 & 8 & 10 \\
\hline 15 & $41 / 2$ & $\mathrm{~F}$ & $\mathrm{R}$ & C & M3-L3 jn & 45 & C & 6 & 2 & 6 & 6 & 10 & 12 \\
\hline 16 & 15 & $M$ & $R$ & C & M3 & 26 & C & 7 & 2 & 8 & 10 & 12 & 14 \\
\hline
\end{tabular}

The school authorities consented to this and allowed an attendant for the children.

Full weight bearing was allowed after clinico-radiological fracture union. Union was defined clinically by the absence of bony tenderness and abnormal mobility at the fracture site, and no pain at the fracture site on weight bearing. Radiological fracture union was defined by the presence of callus bridging the fracture and partial obliteration of the fracture line in 2 views perpendicular to each other.

The children were assessed for malunion both linear and rotational, and limb length disparity.

The wires were removed under general anaesthesia with the help of pliers, which can be locked onto the wire and hammered on.

\section{Results}

The children were aged 2 years to 15 years. There were 7 left sided and 8 right-sided fractures, and 1 bilateral. 14 children had met with a road traffic accident and 2 had a fall from a height. All were closed fractures [Table 2].

There were 6 subtrochanteric, 8 midshaft and 3 distal fractures. One child had bilateral femoral shaft fractures [Figure 3]. 3 fractures were communited. 12 children had associated injuries and 10 children had polytrauma [Table $1]$.
Table I: Associated injuries

\begin{tabular}{ll}
\hline Associated injuries & Patients \\
\hline Eye abrasion & $\mathrm{I}$ \\
Ipsilateral tibia and fibula fractures & 2 \\
Humerus fracture & $\mathrm{I}$ \\
Blunt abdomen injury & 5 \\
Blunt chest injury & $\mathrm{I}$ \\
Brain injury & 7 \\
Clavicle fracture & $\mathrm{I}$ \\
Facial injury & $\mathrm{I}$ \\
Ipsilateral femoral artery tear & $\mathrm{I}$ \\
\hline
\end{tabular}

The average operative time was $40 \mathrm{~min}$ (range 20-72 minutes). Open reduction had to be carried out in 3 fractures, one for an associated femoral artery tear, which needed repair. The other two were for muscle interposition. A percutaneous bone lever was introduced into the fracture site to reduce another fracture. Open reduction needed a minimum exposure with minimum blood loss, minimum handling of the periosteum and, no increase in the morbidity or alteration in the post-operative rehabilitation.

Hospital stay for fracture fixation was between 5-13 days, children with polytrauma stayed longer for treatment of associated injuries. Hospital stay for wire removal was between 2-5 days. Clinico-radiological fracture union was achieved between 6-14 weeks at which time the chil- 


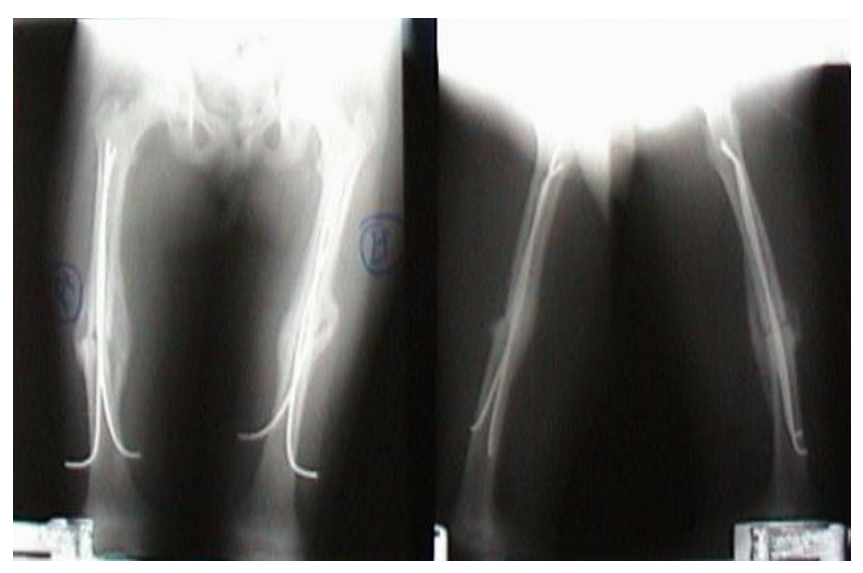

Figure 3

Bilateral femoral shaft fracture.

dren started full weight bearing. The wires were removed between 8-22 weeks [Table 2].

\section{Complications}

Pin track ulceration in 1 child. Pins were trimmed under local anaesthesia and the wounds healed in a week's time.

Exuberant callus formed in 2 children with brain injury, but this did not affect the final outcome.

The fracture angulated in a big child of 14 years. The wires were removed and a closed interlocked medullary nailing was carried out. The fracture went on to union without any further complications.

No infections were encountered.

All the children had a complete range of movement of the hip and the knee joints.

No shortening. Lengthening cannot be commented on, as this was a short-term study.

\section{Criteria for malunion [16]}

More than $15^{\circ}$ angulation in coronal plane, $20^{\circ}$ in sagittal plane, and $10^{\circ}$ in rotational malalignment is unacceptable. This is variable with age with as much as $45^{\circ}$ angulation in sagittal plane being acceptable in infants due to the remodelling potential.

\section{Discussion}

Long years of experience and study have established the place of surgical management of femoral shaft fractures in children. Of the various modalities, ESIN is proving to be the best surgical option.

The aim is to encourage the formation of bridging periosteal callus. The wires, the bone and the muscles provide the stability. The muscles act as guy ropes, so even in an irritable child or the hyperactive child, the muscle activity just complements the fixation. Muscle action also causes spontaneous correction of any angular deformities. Micromotion allowed by the elasticity of the fixation promotes external bridging callus. The periosteum is not disturbed and being a closed procedure there is no evacuation of the fracture haematoma or risk of infection. Callus formation is twice as fast as with conventional methods [6].

In this study the wires were not pre-bent to a ' $\mathrm{C}$ ' or ' $\mathrm{S}$ ' curve. Kiely [20] studied the construct of C, S and straight intramedullary wires in a model simulating a fractured femur of a 6 years old child. He concluded that the principle of flexible nailing does not apply to children's femoral shaft fractures. The factor may be the small diameter of the model used in the study. He also concluded that any of the described nail combinations could be used to stabilise a small diameter bone. This provides the surgeon with a greater range of options when managing fractures. The present study agrees with these findings.

In this study, retrograde wiring was used for 2 distal fractures and a single ante grade wire for another distal fracture achieving good results. Other researchers have not reported operating on a child as young as 2 years.

In this study, children were allowed to continue normal activities after removal of the wires.

This short-term study compares well with other studies on treatment of femoral shaft fractures in children by both conservative and operative methods. It agrees with other studies on elastic nailing with titanium nails and stainless steel Kirschner wires.

Staheli [15] defined the ideal treatment of femoral shaft fractures in children as one that controls alignment and length, does not compress or elevate the extremity excessively, is comfortable for the child and convenient for the family, and causes the least negative psychological impact possible. This technique comes close to achieving this ideal.

\section{Conclusion}

Intramedullary nailing of femoral shaft fractures in children by stainless steel Kirschner wires is an effective method, which compares well with other studies. It is a simple procedure, which can be easily reproduced. Blood 
loss is minimal, and the operative time short. There is no need pre-bend the wires in a $\mathrm{C}$ or S curve. Stainless steel Kirschner wires are cheap, universally available, and can be manufactured locally. The cost of Image intensifiers is affordable in most of the cities of the developing countries. The hospital does not have to maintain a costly inventory. Provides early mobility, return to home and, school. Gives a predictable clinical pathway and reduces occupancy of hospital beds.

The technique was successfully applied for internal fixation of other diaphyseal fractures in children and some selected diaphyseal fractures in adults. Based on my experience and a review of the literature, I recommend this technique as a modality for treatment of femoral shaft fractures in children aged 2 to 14 years.

\section{Competing interests}

The author(s) declare that they have no competing interests.

\section{Acknowledgements}

I thank the staff of King Khalid hospital, Najran, Kingdom of Saudi Arabia; especially, my colleagues from the department of Orthopaedics and the Orthopaedic theatre staff. Of course, no study would be complete without the generous involvement of the patients and their families who extended their confidence in this surgical technique. Many thanks are due to my wife, Dr. Supriya and my lovely children Kanaad and Keya.

\section{References}

I. Shakeel Qidwai A, Zafar Khattak L: Treatment of femoral shaft fractures in children by intramedullary Kirschner wires. The Journal of Trauma: Injury, Infection and Critical Care 2000, 48(2):. 1076606/I/00/4802-0256

2. Rita Huber I, Keller : Flexible intramedullary nailing as fracture treatment in children. I of Paed Orthop 1996, 16:602-605.

3. Rush LV: Dynamic intramedullary fracture fixation of the femur: reflections on the use of the round rod after 30 years. Clin Orthop 1968, 60:21-7.

4. Ender J, Simon-Weidner R: Fixierung trochanterene Frakturen mit elastischen kondylennägeln. Acta Chir Austr 1970, I:40.

5. Pankovitch AM: Flexible intramedullary nailing of long bone fractures: a review. J Orthop Trauma 1987, 1:78-95.

6. Ligier JN, Metaizeau JP: Elastic Stable Intramedullary Nailing of femoral shaft fractures in children. J Bone Joint Surg [Br] | 988, 70B:74-7.

7. Pradeep Kumar: Indian Journal of Orthopaedics. 200I, 35(4):242-244.

8. Salem Al-Zahrani : Saudi Medical Journal. 1998, 19(I):41-44.

9. Aronson J, Torsky EA: External fixation of femur fractures in children. J Pediatr Orthp 1992, 12:157-63.

10. Van Neikerk JL, Dooren DP: Indications and results of osteosynthesis by plate fixation of femoral shaft fractures in children. Neth J Surg 1987, 39:|29-31.

II. Ward WT, Levy J, Kaye A: Compression plating for child and adolescent femur fractures. J Paediatr Orthop 1992, I 2:626-32.

12. Beaty JH, Austin SM, Canale ST: Interlocking intramedullary nailing of femoral shaft fractures in adolescents: preliminary results and complications. J Pediatr Orthop 1994, I4:178-83.

13. Gonzalez-Herranz P: Intramedullary nailing of the femur in children: effects on its proximal end. J Bone Joint Surg [Br] I995, 77-B:262-6.

14. Saxer U: Fractures of the shaft of the femur. In Treatment of fractures in children and adolescents Volume 268. Edited by: Weber BG, Brunner Ch, Freuler F. Berlin, etc; Springer - Verlag; 1980:73-91.
15. Staheli L, Sheridan G: Early spica cast management of femoral shaft fractures in young children. Clin Orthop 1977, 126:162.

16. Campbell's Operative Orthopaedics,. 9.

17. Hansen TB: Fractures of the femoral shaft in children treated by an A.O. compression plate. Acta Orthop Scand 1992, 63:50-52.

18. Canale ST, Tolo VT: Fractures of the femur in children. I Bone Joint Surg Am 1995, 77:294-3I5.

19. Krettek C, Haas N, Walker J, Tscherne H: Treatment of femoral shaft fractures in children by external fixation. Injury I99|, 22:263-266

20. Kiely Nigel: Mechanical properties of different combinations of flexible nails in a model of a paediatric femoral fracture. Paed Orthop 2002, 22:424-427.

21. Mirdad Tarek: Operative treatment of femoral shaft fractures in children: a nine-year experience in a Saudi Arabian population. Injury 2000, 31 (10):769-77I.

22. Reeves RB: Internal fixation versus traction and casting of adolescent femoral shaft fracture. J Pediatr Orthop 1990, 19:551.

\section{Pre-publication history}

The pre-publication history for this paper can be accessed here:

http://www.biomedcentral.com/1471-2482/5/6/prepub
Publish with Biomed Central and every scientist can read your work free of charge

"BioMed Central will be the most significant development for disseminating the results of biomedical research in our lifetime. " Sir Paul Nurse, Cancer Research UK

Your research papers will be:

- available free of charge to the entire biomedical community

- peer reviewed and published immediately upon acceptance

- cited in PubMed and archived on PubMed Central

- yours - you keep the copyright
BioMedcentral 